\title{
Incidence of foot and mouth disease and its effect on milk yield in dairy cattle at Andassa dairy farm, Northwest Ethiopia
}

\author{
Hailu Mazengia ${ }^{1}$, Mengistie Taye ${ }^{2}$, H. Negussie ${ }^{3}$, S. Alemu ${ }^{3}$ and Asaminew Tassew ${ }^{4}$ \\ ${ }^{1}$ Assistant Professor, Bahir Dar, University, College of Agriculture and Environmental \\ Sciences, Department of Animal Production and Technology, Bahir Dar, Ethiopia, \\ P.O.Box:276, Mob. Phone; +251-0918-4647, E-mail: hailumakida@yahoo.com \\ ${ }^{2}$ Assistant Researcher, Andassa Livestock Research Center, P.O. Box 27: Bahir Dar, \\ Ethiopia \\ ${ }^{3}$ Assistant Professor, Gondar University, Faculty of Veterinary Medicine. P.O.Box: 196, \\ Gondar, Ethiopia \\ ${ }^{4}$ Lecturer, Bahir Dar ,University, College of Agriculture and Environmental \\ Sciences, Department of Animal Production and Technology, Bahir Dar, Ethiopia, \\ P.O.Box:276
}

\begin{abstract}
A study on incidence of foot and mouth disease (FMD) was conducted at Andassa Government Dairy Farm during July to August 2008 with the objective of determining the incidence rate and to evaluate the effect of the disease on milk yield. The overall incidence of foot and mouth disease in dairy cattle of the farm was $14.55 \%$. The incidence rate in Fogera cattle $(15.52 \%)$ was significantly $(p>0.05)$ higher than that of Holstein-Friesian cross cattle $(2.50 \%)$. The average milk yield ahead of 10 days of FMD infection $(1182.86 \pm 32.13)$ was found significantly $(p<0.05)$ higher than that of the milk yield 10 days after infection $(602.86 \pm 18.86)$. The overall mortality rate of the disease was $2.24 \%$ during the study period and the mortality rate in cross cattle $(2.50 \%)$ was found higher than that of Fogera cattle $(2.22 \%)$. In conclusion, the results of this study indicated that the complex epidemiological situation of the disease in Ethiopia needs more detailed investigation for improved vaccine-based control is to be achieved efficiently.
\end{abstract}

Keywords: Andassa, Dairy Farm, Foot and Mouth Disease, Incidence.

\section{INTRODUCTION}

Foot and Mouth Disease (FMD) is one of the most devastating disease of cloven-footed animals caused by a group of seven antigenically different serotypes of extremely contagious and has a great potential for causing severe economic loss to both livestock and agricultural production. FMD is endemic in majority of developing countries (Cottral et al 1970; Robertson, 1976; Brown, 1985). It is not only results in severe In Ethiopia, FMD is a notifiable disease and the Federal Veterinary Service sends official reports to Office of International Epizootics (OIE) monthly and annually (CSA, 2006). This endemic disease is characterized by expanding boundaries and increasing total incidences (Asfaw and Sintaro, 2000). Fore example, during the periods from 1988 to 1991 sixteen FMD outbreaks were recorded. The records from Food and Agriculture (FAO) World production losses of infected animals, but also loss of export potential of livestock and livestock products which could be instrumental in the development of livestock sector in developing countries(Senturk and Yalcin 2005;Aftosa 2005). This disease causes significant financial losses (Perry et al 1999). The cost incurred for control or eradication is quite high. Besides, there are major indirect losses due to the imposition of trade restrictions (Anonymous 2001).

Reference Laboratory (WRL) indicates that FMD serotypes $O, A, C$ were responsible for FMD outbreaks during the period1957 to 1979(Roeder et al 1994).

Recently, it had become the major constraint hampering export of livestock and livestock products to the Middle East and African countries. Fore instance, the Egyptian trade ban export of live animal livestock products, in which Ethiopia can lose. 
14 million \$US annually (Leforban, 2005). Such losses and the strict requirements of international trade warn Ethiopia to control the disease. Therefore, the objective of this study is to determine the incidence of foot and mouth disease and the effect of FMD infection on milk yield at Andasa Government Dairy Farm

\section{MATERIALS AND METHODS}

Study area: The study was conducted at Andasa Government Dairy Farm, which is located 600 km northwest of the capital, Addis Ababa, Ethiopia. The elevation of the area is 1,780 meter above sea level. The annual temperature and rainfall in the study area were about $9-34{ }^{\circ} \mathrm{C}$ and $900-1500 \mathrm{~mm}$, respectively (CSA, 2006). The wet season lasts from April to September whereas the dry season extends from October to March (BoARD, 2007).

Study Animals and Management: The farm was established for the purpose of conservation and improvement of local indigenous Fogera breed by Government of Ethiopia in 1964. More recently, Fogera were crossed with Holstein-Friesian cattle to produce pregnant cross heifers for farmers engaged in small holder dairy farming activities so as to enhance the income of farmers. A total of 536 dairy cattle are being kept in the farm and the number of Fogera $(n=496)$ cattle was higher than that of crosses (Holstein-Friesian $x$ Fogera $n=40$ ), of nucleus herds. Cross cattle are fed concentrate and cultivated forage and partially kept in door during night; however, indigenous Fogera cattle are kept with minimum inputs mostly free grazing only.

Based on their age, study animals were conventionally grouped in to two age groups, above ten years (44 animals) and ten and below ten years of age (492 animals).

Study Design: A longitudinal study design was implemented in this study. Accordingly, the cattle were closely observed daily for one month (i.e. July to August 2008). Sick cattle were isolated and the clinical signs manifested were recorded and followed separately until they recovered or died. The diagnosis of the disease was made on the basis of clinical signs manifested and suggestive of foot and mouth disease. Sick cattle with the clinical signs of sudden lameness in a number of animals, loss of appetite, a sudden drop in milk yield, fever, anorexia, salivation and presence of vesicular lesion on mouth, feet and hooves were isolated, recorded and followed separately until they recovered to determine the incidence.
Epidemiological information was recorded and animals were clinically examined for presence of FMD lesions on the mouth and feet and specimen (sera) were collected for confirmation. The daily milk yield of infected cows was recorded daily for twenty days (10 days before and after each cow has been sick) to evaluate its effect of milk yield.

Serology: For confirmation, blood from individual sick cattle was collected aseptically; sera were separated and submitted to National Veterinary Institute (NVI) for detection of FMD anti-body to FMD virus (OIE, 2002). Accordingly, an ELISA test (Ceditest FMD ELISA, from Netherlands produced by cedi-diagnostic.B, $V$ in 2001) was performed. The Ceditest foot and mouth virus-Non-structural protein (NSp) is a blocking ELISA that detects antibodies directed against the non structural $3 A B C$ protein of foot and mouth disease virus (FMDV). The ELISA detects FMDV infected animals independent of the serotype that cause infection and independent of whether an animal has been vaccinated (Wiesław and Bernd, 2003).

About $100 \mu \mathrm{l}$ of pre-diluted samples using ELISA buffer and ready to use controls (negative, weak positive and strong positive controls) were dispensed into the appropriate wells of the micro titer plate precoated with recombinant FMD $3 A B C$ viral antigen. The plates were sealed using the enclosed plate sealer and incubated overnight (16-18hrs) at room temperature $\left(20-25{ }^{\circ} \mathrm{C}\right)$. After incubation, microplates were filled with about $100 \mu$ l washing fluid and washed six times then $100 \mu \mathrm{l}$ of working dilution of the conjugate was dispensed to all wells. Incubated for 1 hour at room temperature $\left(20-25^{\circ} \mathrm{C}\right)$, and then emptied the test plate after the incubation period and

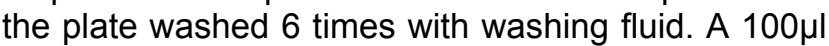
chromogen or substrate solution was dispensed into each well and incubated for 20minuites at room temperature $\left(20-25^{\circ} \mathrm{C}\right)$. Finally, $100 \mu$ l of stop solution was added to all wells and the results were read using a spectrophotometer at $450 \mathrm{~nm}$ wavelength to obtain the optical density (OD)(OIE,2002).

The ODs of all samples including the controls were calculated and are expressed as the percent inhibition $(\mathrm{PI})$ as follows: $\mathrm{PI}=100-\left[\left(\mathrm{OD}_{450}\right.\right.$ of test sample)/ (mean $\mathrm{OD}_{450}$ of negative controls)] x 100. A $\mathrm{PI}$ of $<50 \%$ was considered negative and a $\mathrm{PI}$ of $\geq$ $50 \%$ was considered positive for exposure. More specifically, a $\mathrm{PI}$ value of $\geq 50 \%$ but, $<70 \%$ was considered a weak positive result and a PI value of $\geq$ $70 \%$ was considered a strong positive. 
Data Analysis: The data were analyzed using descriptive statistics, and Chi-square test was used for comparison of incidence. The incidence rate was calculated by dividing the number of new cases from FMD in a month to the population at risk at the beginning of the month and multiplying the result by hundred (Thrusfield, 2005)

Independent t-test was utilized for comparison of milk yield before and after 10 days of the infection of foot and mouth disease in 14 lactating cows. Tests were considered significant at $p \leq 0.05$.

\section{RESULTS}

The main clinical signs observed were inappetance loss of condition salivation, fever, anorexia, marked drop in lactation, abortion and lameness were recorded in FMD infected cattle. Vesicular lesions consisted of erosions and ulcers mainly on the tongue and hooves were observed Foot lesions comprised erosions on the interdigital spaces and on the coronary bands. On the latter, the lesions were so severe that the hoof tended to separate from the coronary band. Most affected cattle showed both mouth and foot lesions (figure $1 \mathrm{a} \& \mathrm{~b}$ ).

From a total of 536 cattle observed during the study period, $14.55 \%$ (78 of 536 ) and $2.24 \%$ (12 of 536 ) cattle were affected and dead with foot and mouth disease respectively, during the outbreak of the disease. Higher rate of incidence, $15.52 \%$ (77 of 496), was calculated in Fogera breeds and was statistically significant $(p>0.05)$ than that of the incidence, $2.50 \%$ (1 of 40 ) in cross-breeds. The incidence of FMD in dairy cattle above 10 years of age $18.18 \%$ (8 of 44 ) was higher than the incidence,
$14.22 \%$ (70 of 492 ), of the group in less than or equal to ten years; however, no statistically significant difference $(p>0.05)$ between the incidence of FMD between the two age groups.The overall mortality rate of the disease was $2.24 \%$ during the study period and the mortality rate in cross cattle $(2.50 \%)$ was found higher than that of Fogera cattle $(2.22 \%)$. However, no any significant difference in mortality rate is detected between breeds, Similarly, from the total of 463 cattle $1.30 \%$ (7 of 463 female cattle) aborted. Include the following paragraph next to the above. There was higher rate of incidence in female $(16.63 \%)$ cattle than that of male cattle $(1.37 \%)$ in the farm. However, no any significant difference was detected between female and male cattle (Table 1).

The effect of Foot and mouth disease on milk yield: On-farm evaluation of the milk yield performance of Fogera cattle was conducted in the dairy farm. For this purpose 70 cattle were included in milk yield evaluation out of this only 14 of them were found infected with FMD. The milk yield of the 14 foot and mouth disease infected dairy cows was observed by analyzing the milk yield before and after 10 days of infection. The average milk yield (gm) before 10 days of FMD infection $(1182.86 \pm 32.13)$ was higher than that of after 10 days of infection $(602.86 \pm 18.86)$. Moreover, there was statistical significant $(p<0.05)$ difference in average milk yield between before and after ten days of infection. The mean milk yield in parity-two foot and mouth disease infected cows $(987.50 \pm 58.640)$ was higher than parity-one, three and four cows. However, no significant difference $(p>0.05)$ in average milk yield was observed among different parity cows

Tabe 1. Descriptive and analytic results of the potential risk factors associated with foot and mouth disease in dairy cattle at Andasa Government Dairy Farm

\begin{tabular}{lcccccc}
\hline Risk factors & $\begin{array}{c}\text { No. at } \\
\text { risk }\end{array}$ & $\begin{array}{c}\text { No. } \\
\text { affected }\end{array}$ & Incidence (\%) & $95 \% \mathrm{Cl}$ Incidence & Mortality rate (\%) & $95 \%$ Cl Mortality \\
\hline $\begin{array}{l}\text { Breed } \\
\quad\end{array}$ & & & & & & \\
$\quad$ Fogera & 496 & 77 & 15.52 & $12.6-18.9$ & 2.22 & $0.01-0.03$ \\
$\quad$ Cross & 40 & 1 & 2.50 & $0.6-12-8$ & 2.50 & $0.00-0.12$ \\
$\quad$ Total & 536 & 78 & 14.55 & $11.8-17.8$ & 2.24 & $0.01-0.03$ \\
Age group & & & & & & \\
$\quad>10$ years & 44 & 8 & 18.18 & $9.6-3.2$ & 0.00 & $0.00-0.08$ \\
$\quad \leq 10$ years & 492 & 70 & 4.22 & $11.4-17.5$ & 2.24 & $0.01-0.03$ \\
\hline
\end{tabular}




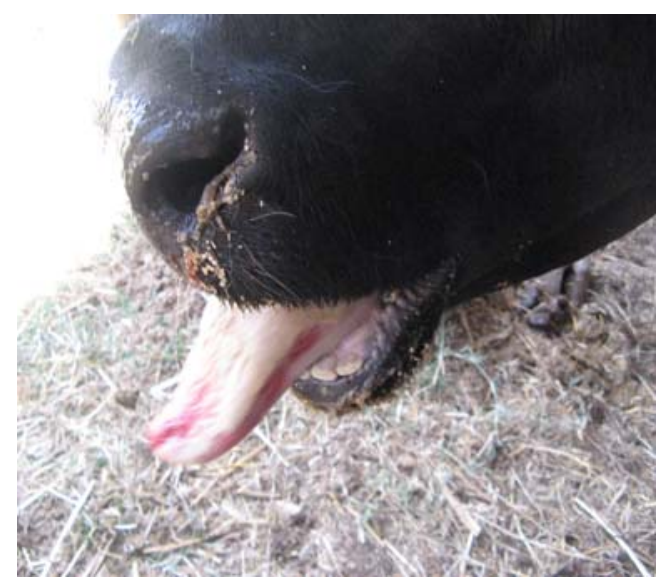

(a)

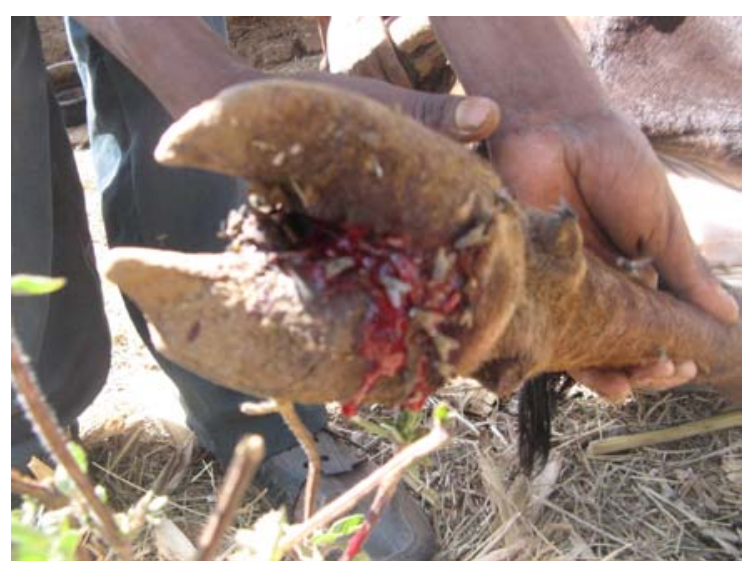

(b)

Fig 1. Gross lesion observed in the oral cavity (figure a) and foot (figure b) of foot and mouth disease infected dairy cattle at Andassa Government Dairy Farm.

Table 2. Average milk yield across different parity and milking days in FMD infected Dairy cows at Andassa Government Dairy Farm

\begin{tabular}{|c|c|c|}
\hline Variables & $\begin{array}{l}\text { Average milk yield } \\
(\mathrm{mg}) \quad(\text { Mean } \pm \mathrm{SE})\end{array}$ & P-value \\
\hline \multicolumn{3}{|l|}{ Parity of infected cows } \\
\hline One & $876.50 \pm 32.81$ & $P=0.13$ \\
\hline Two & $987.50 \pm 58.64$ & \\
\hline Three & $885.00 \pm 77.89$ & \\
\hline Four & $945.00 \pm 32.83$ & \\
\hline \multicolumn{3}{|l|}{ Milking days } \\
\hline Before FMD infection & $1182.86 \pm 32.13$ & $p=0.001$ \\
\hline After FMD infection & $602.86 \pm 18.86$ & \\
\hline
\end{tabular}

\section{DISCUSSION}

In recent times, foot and mouth disease become series disease problem in Ethiopia. According to the reports of Bureau of Agriculture and Rural Development Office episode of foot and mouth disease outbreaks are common at intervals of decades (Asfaw and Sintaro,2000;BoARD, 2007; Rufael et al 2007). During the study periods many focal outbreaks were reported by livestock owners and experts on the occurrence of the disease in the cattle of the farmers around the Andassa Government Dairy Farm (BoARD, 2007).

The incidence rate in indigenous Fogera cattle $(15.52 \%)$ was higher than crossbreds (Fogera $\mathrm{x}$ Holstein-Friesian) (2.50\%). The mortality rate due to the disease was, however, lower in Fogera bred $(2.22 \%)$ than crossbred $(2.50 \%)$. The higher incidence of the disease in indigenous Fogera cattle compared to cross breeds might be due to the suboptimum management practices implemented on Fogera breed cattle as they were supplemented with minimum inputs due to their low production and body weight gain. Fogera bred cattle are usually let to graze at the periphery of the center, therefore, the higher level of incidence might be due to higher frequency of contact with infected animals of the nearby farmers which increase the degree of acquiring FMD. Despite its endemic occurrence in Ethiopia (Asfaw and Sintaro, 2000; James and Rushton, 2002; Rufael et al. 2007) and establishment of genetic adaptability, the higher level of incidence of FMD in Fogera bred cattle might be due to presence of actual difference in susceptibility between Fogera bred cattle and the Holstein-Friesian which might contribute unknown factor for resistance to crossbred cattle. As it is known, the direct impact of FMD on livestock in sub-Saharan Africa depends on the type of farming and the breeds of animals used (Hunter, 1998). They are usually kept with relatively higher density of herd that could increase the transmission of the disease among susceptible groups (Susan and Asamays, 1998).

The higher rate of incidence in female $(16.63 \%)$ cattle than that of male cattle $(1.37 \%)$ might be due to the 
physiological stressors which include estrus, pregnancy and lactation which are known to affect their resistance to infection (Susan and Asamays, 1998). On the other hand, the incidence rate of FMD in cattle above 10 years of age (18.18\%) was found higher than ten that of ten years of age $(14.22 \%)$. This is not in agreement with Rufael et al. (2007), who reported that in Ethiopia the estimated mean incidence of acute FMD, varied from in $18.5 \%$ in cattle less than two years of age to $14.0 \%$ in cattle three to four years of age.

In this study, the impact of FMD infection on milk yield of dairy cows has been observed; the milk yield before ten days of infection $(1182.86 \pm 32.13 \mathrm{mg})$ was higher than that of after ten days of infection $(602.86 \pm 18.86 \mathrm{mg})$ and the difference between the average milk yield of the fourteen milking cows before and after ten days of infection was statistically significant $(P<0.05)$. This finding is in line with other reports due to the fact that FMD cause tremendous reduction of milk yield in infected cows (Susan and Asamays, 1998; James and Rushton, 2002) as the result of causing reduced consumption of feed due to painful tongue and mouth lesions, which influences weight gain and milk production.

In conculusion, it is paramount important that the presence of foot-and-mouth disease in Ethiopia is a major obstacle to the development of agriculture because of its adverse effects on livestock production and agricultural exports. During the study periods, FMD had a greatest impact on livestock production by causing mortality and morbidity and reduce the daily milk yield. Therefore, an extensive regular serological survey, virus isolation, and characterizations of foot and mouth disease virus need to be conducted for a possible development of vaccines which contains cocktails of antigens of FMD virus strain in Ethiopia. Furthermore, the complex epidemiological situation of FMD in Ethiopia needs more detailed investigation for improved vaccine-based control is to be achieved efficiently so as to make a disease free zone.

\section{REFERENCES}

Aftosa F (2007). Foot and Mouth Disease (FMD). The Center for Food Security \& Public Health. lowa State University, College Veterinary Medicine, pp.1-3.

Anonymous (2001).International Animal Health Code $10^{\text {th }}$ edition Paris France: Office International des Epizooties Chapter 2.1.1. Foot and mouth Disease.

Asfaw W, Sintaro T (2000). The status of FMD in Ethiopia, a growing concern. Ethiopian Veterinary Epidemiology Newsletter. Addis Ababa, Ethiopia, 2:1-5.

Brown F, Carroll B, Clarke E, Ouldridge and D. Rowlands (1985). Veterinary Viral Diseases. (Della-Porta, A.J.ED.) Academic Press, Orlando, Florida, pp.265-272.
Bureau of Agriculture and Rural Development of Amhara Regional State (BoARD) (2007). Report,. Annual Report, pp. 5-22.

Central Statistical Agency (CSA) (2006). Report on Livestock Resources of Amhara Region, pp. 23-112.

Cottral G, Shaha and H, Seybold (1970). Foot and Mouth Disease in Baghabari Milk Shed Area and its Economic Loss in Bangladesh. (Gibbons, W.J., E.J. Cacott and J.F.Sithcors, Eds.). Journal of Biological Science, 4 (5):581-583.

Hunter P (1998). Vaccination as a means of control of footand-mouth disease in sub Saharan Africa. Vaccine, 16(3): 261-264.

James A and Rushton J (2002). The economics of foot and mouth disease. OIE Scientific and technical Review, 21 (3): 637-644

Kitching R, Hutber A, and Thrusfield (2005). A review of footand-mouth disease with special consideration for the clinical and epidemiological factors relevant to predictive modeling of the disease. The Veterinary Journal, 169:197-209.

Leforban Y (2005). Report of a mission on foot and mouth disease in Ethiopia. Proposals for a strategic plan for a control program oriented to the export, 10 - 22 April 2005, Pp: $12-42$.

Office International des Epizooties (OIE) (2002).Internetsite:http://www.oie.int/eng/en-index.htm (Accessed August, 2008)

Perry B, Kalpravidh P, Coleman H, Horst J, McDermott T, Randolph $L$ and Gleeson (1999). The economic impact of foot and mouth disease and its control in South-East Asia: a preliminary assessment and its control with its reference to Thailand, OIE, 18(2):478-497.

Roeder P, Abrham G, Membrahm, G' and Kitching R (1994). Foot and Mouth Disease in Ethiopia from 1988 to 1991.Tropical Animal Health and Production, 26:163-167.

Senturk B and Yalcin C (2005) .Financial impact of foot - and mouth disease in Turkey: acquisition of required data via Delphi expert opinion survy.Vet.Med-Czech, 10,451-460.

Susan E and Asamays (1998). The Merck Veterinary Manual (8th Edition), Whitehouse Stat $\mathrm{N} \mathrm{J}$ Merck and Co. inc. 1879.

Thrusfield, MV (2005).Veterinary Epidemiology, Black Wall Science, Great Britain, pp.183.

Wiesław N and Bernd H (2003). Differentiation of infection from vaccination by detection of antibodies to the non-structural protein $3 A B C$ of foot-and-mouth disease virus. Bull. Vet. Inst. Pulawy, 47, 51-60.Robertson A (1976). Handbook on Animal Disease in the Tropics, London: British Veterinary Association.

Rufael T, Catley A, Bogale A, Shale M and Shiferaw (2007). Foot and mouth disease in the Borana pastoral system, southern Ethiopia and implications for livelihoods and international trade. Tropical Animal Health and Production, pp.28-38. 